Andrija Oliveira Almeida ${ }^{1}$ Marco Valério Viana Freire ${ }^{2}$

\title{
DIREITO À SAÚDE NO BRASIL: RESERVA DO POSSÍVEL E MÍNIMO EXISTENCIAL NAS DECISÕES DO SUPERIOR TRIBUNAL DE JUSTIÇA (2010-2016)
}

Right to health in Brazil: Use of reserves and basic human dignity in the decisions of the Brazilian Superior Court of Justice (2010-2016)

${ }^{1}$ Universidade Federal da Bahia. Salvador/BA, Brasil.

${ }^{2}$ Universidade Católica do Salvador. Salvador/BA, Brasil.

Correspondência: Andrija Oliveira Almeida. E-mail: andrija.oliveiraalmeida@gmail.com

Recebido: 08/04/2017. Revisado: 10/04/2018. Aprovado: 18/04/2018. 


\section{RESUMO}

O objetivo do trabalho é analisar as características das decisões do Superior Tribunal de Justiça entre 2010 e 2016 concernentes à aplicabilidade, ao direito à saúde no Brasil, das cláusulas da reserva do possível e do mínimo existencial, a partir da interface entre o direito e a política. O estudo insere-se na abordagem empírica da pesquisa em direito, com enfoque qualitativo e do recurso à análise documental. $\mathrm{O}$ corpus de dados constituiu-se de 15 decisões coletadas na base eletrônica de julgados do Superior Tribunal de Justiça. A análise dos dados evidencia que o entendimento da Corte sobre a efetivação do direito à saúde caracteriza-se pelo argumento da não "oponibilidade da reserva do possível ao mínimo existencial" em matéria de saúde e pela determinação ao Poder Executivo da obrigação de fazer e da admissibilidade do bloqueio de verbas públicas, mormente quando se trata de garantia de acesso a medicamentos. Ademais, nas decisões judiciais estudadas neste trabalho há destaque para a refutação jurídico-política da ideia de separação de poderes como fator impeditivo à edição de mandamento realizador pelo Poder Judiciário em matéria de direitos sociais, bem como para a demarcação do conteúdo jurídico do mínimo existencial constitutivo do direito fundamental à saúde e, desse modo, do estabelecimento da extensão das prestações positivas do Estado.

\section{Palavras-Chave}

Direito à Saúde; Estado Social; Mínimo Existencial; Reserva do Possível; Superior Tribunal de Justiça.

\section{ABSTRACT}

This paper aims at analyzing the characteristics of decisions from the Brazilian Superior Court of Justice between 2010 and 2016, related to the applicability of provisions of contingency reserves and basic human dignity to the right to health in Brazil, from the relationship between law and politics. The study uses the empirical approach of research in law, applying qualitative methods and document analysis. The data corpus is composed by fifteen decisions collected from the Superior Court electronic database. The analysis of data shows that the Court's understanding on the implementation of the right to health is characterized by the argument of no "opposition of contingency reserves to basic human dignity" with regard to health matters, by the determination that the Executive has the obligation to perform, and the admissibility of the blockage of public funds, primarily when it comes to ensuring access to medicines. Moreover, in the judicial decisions studied in this paper the legal-political refutation is highlighted regarding the idea of separation of powers as an obstacle for the Judiciary Branch edit a command on matters of social rights, as well as determine the legal contents of basic human dignity that is part of the fundamental right to health and, in this way, establish the extent of the state's positive social benefits.

\section{Keywords}

Basic Human Dignity; Brazilian Superior Court of Justice; Contingency Reserve; Right to Health; Social Welfare State. 


\section{Introdução}

O debate jurídico sobre mínimo existencial e sobre reserva do possível tem origem na doutrina alemã, respectivamente nas décadas de 1940 e $1970^{1}$, mas possui interfaces com discussões mais amplas tocantes a transformações sociopolíticas da relação Estado/sociedade/mercado, decorrentes do processo de industrialização e modernização das sociedades ocidentais e cujos aspectos foram recuperados como chave de leitura para a contextualização da análise das decisões do Superior Tribunal de Justiça (STJ) sobre o direito à saúde no Brasil entre 2010 e 2016, fundamentadas nos aludidos institutos originários do Direito alemão.

Nesse sentido, retomam-se pontos de contato entre elementos da formação histórica e da expressão jurídico-política dos Welfare States - que, no âmbito do Estado Capitalista, entende-se como uma forma particular de regulação social que se expressa pela transformação das relações entre o Estado e a economia, entre o Estado e a sociedade, a um dado momento do desenvolvimento econômico ${ }^{2 "}$ - e dos sistemas de proteção social nascidos na Europa ao final do século XIX e desenvolvidos durante o século XX, em suas especificidades, variações históricas e também em contextos socioeconômicos de capitalismo tardio (como o do Brasil).

Na Europa do final do século XIX, fatores como industrialização, urbanização, consolidação do corpo burocrático estatal e domínio de técnicas administrativas, associados à mobilização política de movimentos sociais, concorreram para a institucionalização de complexos de proteção social nos Estados nacionais.

Para Sonia Fleurye Assis Mafort Ouverney ${ }^{3}$, não obstante a ocorrência de diversos arranjos nacionais segundo a especificidade histórica e social de cada realidade, é possível descrever três tipos ideais de sistemas de proteção social que se distinguem no tocante à concepção de políticas sociais e de suas instituições, quais sejam:

(i) O modelo de assistência social: É denominado modelo residual, orientado por valores como liberdade, individualismo e igualdade de oportunidades para competição no mercado. Organiza-se a partir de fundos e doações, e a ação pública é de caráter emergencial, pontual e focalizada na pobreza e nos grupos vulneráveis.

(ii) O modelo do seguro social: Consiste no modelo implementado na Alemanha por Bismarck e pressupõe "o condicionamento dos direitos sociais pela inserção

\footnotetext{
${ }^{1}$ SARLET, Ingo Wolfgang; FIGUEIREDO, Mariana Filchtiner. Reserva do possível, mínimo existencial e direito à saúde: algumas aproximações. In: SARLET, Ingo Wolfgang; TIMM, Luciano Benetti (Orgs.). Direitos fundamentais: orçamento e "reserva do possível". Porto Alegre: Livr. do Advogado, 2013. p. 13-50.

${ }^{2}$ DRAIBE, Sônia. O Welfare State no Brasil: características e perspectivas. Caderno de Pesquisa, Campinas, n. 8, 1993. Disponível em: <https://sociologiajuridica.files.wordpress.com/2011/10/o-welfare-state-nobrasil-caracterc3adsticas-e-perspectivas-sonia-draibe.pdf>. Acesso em: 23 maio 2016.

${ }^{3}$ FLEURY, Sonia; OUVERNEY, Assis Mafort. Política de saúde: uma política social. In: GIOVANELLA, Ligia et al. (Org.). Políticas e sistema de Saúde no Brasil. Rio de Janeiro: FIOCRUZ: CEBES, 2008. p. 23-64.
} 
dos indivíduos no mercado de trabalho"4, sendo que as prestações positivas são proporcionais à contribuição dos beneficiários. As categorias jurídicas "reserva do possível" e "mínimo existencial" têm assento no âmbito deste modelo de proteção social.

(iii) O modelo da seguridade social: Tem como referência sócio-histórica o Plano Beveridge, implantado no início dos anos 1940 na Inglaterra. Caracteriza-se pela universalização das prestações sociais e pela desvinculação dos benefícios à existência de contribuição prévia. Segundo Sonia Fleury e Assis Mafort Ouverney, consiste "em um novo modelo de ordem social baseado na condição de cidadania, segundo a qual os cidadãos passam a ter seus direitos sociais assegurados pelo Estado".

No Brasil, segundo Sônia Draibe ${ }^{6}$, a formação e a consolidação institucional do Estado Social datam historicamente do período compreendido entre os anos 1930 e a década de 1970. A gênese do Estado Social brasileiro, para a autora, foi marcada por mudanças no regime político, na forma de Estado e nas relações entre a política social e a política econômica, o que nos permite identificar, em diferentes períodos históricos, as complexas expressões do Welfare State na sociedade brasileira, cujo padrão conformou tendências e moldagens meritocráticas e residuais (1930-1964), particularistas (1964-1985) e universalistas (1985-1988).

Considerando os objetivos deste trabalho, é importante ressaltar que o processo de institucionalização da proteção social enquanto atividade coletiva, segundo os moldes do sistema da seguridade, se expressa juridicamente nos diversos contextos sob a "forma de direitos garantidores da condição ou status de cidadania"'.

Do ponto de vista jurídico, isso implica a transformação de um direito em função estatal ${ }^{8}$, com desdobramentos teóricos e práticos para o campo do direito e para a conformação do ordenamento jurídico atinentes, entre outros, aos seguintes aspectos: reorganização das relações entre o cidadão e o Estado a partir da relação de direito positivo; constituição do direito social enquanto forma jurídico-legal'; configuração da jusfundamentalidade formal e material dos direitos sociais ${ }^{10} \mathrm{e}$ das prestações positivas nos ordenamentos nacionais; e tensão entre os sistemas político

\footnotetext{
${ }^{4}$ FLEURY, Sonia; OUVERNEY, Assis Mafort. op. cit., p. 35.

${ }^{5}$ Id., loc. cit.

${ }^{6}$ DRAIBE, Sônia. O Welfare State no Brasil: características e perspectivas, cit., p. 19.

${ }^{7}$ FLEURY, Sonia; OUVERNEY, Assis Mafort. op. cit., p. 29.

8SARLET, Ingo Wolfgang; FIGUEIREDO, Mariana Filchtiner. Reserva do possível, mínimo existencial e direito à saúde: algumas aproximações. In: SARLET, Ingo Wolfgang; TIMM, Luciano Benetti (Orgs.), cit., p. 13-50.

${ }^{9}$ FLEURY, Sonia; OUVERNEY, Assis Mafort. op. cit.

${ }^{10}$ SARLET, Ingo Wolfgang; FIGUEIREDO, Mariana Filchtiner. Reserva do possível, mínimo existencial e direito à saúde: algumas aproximações. In: SARLET, Ingo Wolfgang; TIMM, Luciano Benetti (Orgs.), cit., p. 13-50.
} 
e do direito no que toca ao paradoxo do controle judicial de políticas públicas e à separação de poderes ${ }^{11,12,13}$.

No caso brasileiro, essa transformação do direito em função estatal articulou-se ao processo de reforma do Estado e à inflexão político-normativa do sistema de proteção social nos anos 1980, com a constitucionalização da seguridade social e a inclusão dos direitos sociais, em particular do direito à saúde, como elemento constitutivo do modelo de proteção social universal. Desse modo, o novo desenho constitucional de proteção social fomentou o debate jurídico brasileiro em torno da efetividade do direito à saúde à luz das categorias "reserva do possível" e "mínimo existencial", configurando-as como marcadores jurídicos dos contornos da atuação do Estado no campo da saúde.

Nessa perspectiva, o objetivo do trabalho é analisar as características das decisões do STJ entre 2010 e 2016 concernentes à aplicabilidade das cláusulas da reserva do possível e do mínimo existencial ao direito à saúde no Brasil, a partir de uma interface entre o direito e a política.

$\mathrm{O}$ estudo insere-se na abordagem empírica da pesquisa em direito com jurisprudência ${ }^{14}$ desde um enfoque qualitativo e recurso à análise documental ${ }^{15}$. O corpus documental constituiu-se de 15 decisões colegiadas, em sua maioria em sede de recurso especial, coletadas na base eletrônica de julgados do STJ (Quadro 1), a partir de busca temática centrada nos descritores "direito à saúde" e "reserva do possível" e "direito à saúde" e "mínimo existencial", assumindo como recorte temporal os julgados do período compreendido entre 2010 e 2016.

Para a composição, organização e análise do corpus, foram obedecidas as seguintes etapas ${ }^{16}$ : (i) busca digital no sítio eletrônico do STJ; (ii) descrição, identificação e codificação dos documentos encontrados; (iii) arquivamento do inteiro teor

\footnotetext{
${ }^{11}$ GRINOVER, Ada Pellegrini. O controle das políticas públicas pelo poder judiciário. Revista do Curso de Direito da Faculdade de Humanidades e Direito, São Paulo, v. 7, n. 7, p. 9-37, 2010. Disponível em: <https://www. metodista.br/revistas/revistas-ims/index.php/RFD/article/viewFile/1964/1969>.

${ }^{12}$ DI PIETRO, Maria Sílvia Zanella. Direito administrativo. São Paulo: Atlas, 2015.

${ }^{13}$ BARBOSA, Leon Victor de Queiroz. O silêncio dos incumbentes: fragmentação partidária e empoderamento judicial no Brasil, 2015. 166f. Tese (Doutorado) - Universidade Federal de Pernambuco, Programa de Pós-Graduação em Ciência Política, Recife, 2015. Disponível em: <https://repositorio.ufpe.br/ bitstream/123456789/15169/1/TESE\%20\%282015-02-23\%29\%20-\%2OLEON\%2OVICTOR\%2ODE\%20 QUEIROZ\%20BARBOSA.pdf>.

${ }^{14}$ VEÇOSO, Fábia Fernandes Carvalho et al. A pesquisa em Direito e as bases eletrônicas de julgados dos Tribunais: matrizes de análise e aplicação no Supremo Tribunal Federal e no Superior Tribunal de Justiça. Revista de Estudos Empíricos em Direito / Brazilian Journal of Empirical Legal Studies, v. 1, n. 1, p. 105139, jan. 2014. ISSN 2319-0817. Disponível em: <http://www.reedpesquisa.org/ojs-2.4.3/index.php/ reed/article/view/10>. Acesso em: 30 mar. 2015. http://dx.doi.org/10.19092/reed.v1i1.10.

${ }^{15}$ CELLARD, André. A análise documental. In: POUPART, Jean. et al. (Orgs.). A pesquisa qualitativa: enfoques epistemológicos e metodológicos. Petrópolis: Vozes, 2010, p. 295-316.

${ }^{16}$ BAUER, Martin W.; AARTS, Bas. A construção do corpus: um princípio para a coleta de dados qualitativos. In: BAUER, Martin. W.; GASKEL, George. Pesquisa qualitativa com texto, imagem e som: um manual prático. Petrópolis, RJ: Vozes, 2003. p. 39-63.
} 
das decisões segundo codificação; (iv) análise e seleção preliminar do material recuperado segundo os objetivos do estudo; e (v) análise final e delineamento do corpus.

Quadro 1. Composição do corpus documental.

\begin{tabular}{|c|c|}
\hline $\begin{array}{l}\text { Descritores de busca } \\
\text { na base eletrônica de } \\
\text { julgados do STJ }\end{array}$ & $\begin{array}{l}\text { Relação dos documentos coletados e codificados para análise/ } \\
\text { decisões judiciais do STJ sobre direito à saúde, reserva do possível e } \\
\text { mínimo existencial entre } 2010 \text { e } 2016\end{array}$ \\
\hline $\begin{array}{l}\text { Reserva do possível e } \\
\text { direito à saúde } \\
\text { x } \\
\text { Mínimo existencial e } \\
\text { direito à saúde }\end{array}$ & $\begin{array}{l}\text { DOCSTJ1- REsp 1366331 / RS RECURSO ESPECIAL2012/0125512-2 } \\
\text { DOCSTJ2 - REsp 1488639 / SE RECURSO ESPECIAL2014/0269119-0 } \\
\text { DOCSTJ3- AgRg no REsp 1107511 / RS AGRAVO REGIMENTAL NO } \\
\text { RECURSO ESPECIAL2008/0265338-9 } \\
\text { DOCSTJ 4- REsp } 1068731 \text { / RS RECURSO ESPECIAL2008/0137930-3 } \\
\text { DOCSTJ } 5 \text { - AgRg no REsp } 1136549 \text { / RS AGRAVO REGIMENTAL NO } \\
\text { RECURSO ESPECIAL2009/0076691-2 } \\
\text { DOCSTJ 8-AgRg no RECURSO ESPECIAL No 1.126.936 - RN } \\
\text { (2009/0042754-4) } \\
\text { DOCSTJ9 - RMS 28962 / MG RECURSO ORDINÁRIO EM MANDAD0 DE } \\
\text { SEGURANÇA2009/0037261-9 } \\
\text { DOCSTJ 10 - REsp 1041197 / MS RECURSO ESPECIAL2008/0059830-7 } \\
\text { DOCSTJ 11-REsp 784241 / RS RECURSO ESPECIAL2005/0160324-8 } \\
\text { DOCSTJ 12-REsp 835687 / RS RECURSO ESPECIAL2006/0098994-9 } \\
\text { DOCSTJ 16 - REsp 811608 / RS RECURSO ESPECIAL2006/0012352-8 } \\
\text { DOCSTJ17- AgRg no REsp 878441 / RSAGRAVO REGIMENTAL NO } \\
\text { RECURSO ESPECIAL2006/0182329-8 } \\
\text { DOCSTJ19-REsp 857502 / RS RECURSO ESPECIAL2006/0138024-6 } \\
\text { DOCSTJ22-AgRg no RECURSO ESPECIAL N 1.479.812 - SC } \\
\text { (2014/0197601-4) } \\
\text { DOCSTJ24-AgRg nos EDcl no AGRAVO EM RECURSO ESPECIAL Nº } \\
\text { 681.618 -MG }\end{array}$ \\
\hline
\end{tabular}

Legenda: STJ - Superior Tribunal de Justiça; REsp - Recurso Especial; AgRg - Agravo Regimental; RMS Recurso Ordinário em Mandado de Segurança; EDcl - Embargos Declaratórios.

Elaboração própria. Fonte: http://www.stj.jus.br/sites/STJ

\section{A saúde como direito fundamental no Brasil: tensões jurídico-políticas no campo da efetivação}

As expressões do direito à saúde no Brasil estão historicamente articuladas às matizes assumidas pelo Welfare State e às características dos modelos de proteção social em nosso contexto. Nesse sentido, para Felipe Asensi ${ }^{17}$, é possível identificar três concepções de saúde coexistentes na sociedade brasileira e com alto grau de

\footnotetext{
${ }^{17}$ ASENSI, Felipe. Direito à saúde: práticas sociais reivindicatórias e sua efetivação. Curitiba: Juruá, 2013. $370 \mathrm{p}$.
} 
institucionalidade no âmbito do Estado e no campo jurídico, quais sejam: a saúde como favor; a saúde como serviço originário de direito trabalhista ou como serviço privado; e a saúde como direito universal.

Esse último sentido social de saúde ganhou força entre o final da década de 1970 e meados dos anos 1980, no contexto de redemocratização do país, quando o movimento da Reforma Sanitária Brasileira pautou na agenda política a questão da democratização da saúde, reivindicando, conforme Jairnilson Paim e Naomar Almeida-Filho ${ }^{18}$, "o reconhecimento do direito à saúde, inerente à cidadania, acesso universal e igualitário aos serviços de saúde e participação social nas políticas e na gestão".

Nessa perspectiva, segundo Felipe Asensi ${ }^{19}$, a atuação do movimento sanitário foi decisiva para a inserção política da temática do direito à saúde na Assembleia Nacional Constituinte, bem como para a elaboração de um novo marco jurídico-institucional sobre a matéria no contexto brasileiro. Para o autor, a mobilização política da sociedade civil acarretou a constitucionalização do direito à saúde como direito fundamental.

Os avanços e desafios enfrentados pela sociedade civil e, principalmente, pelo movimento da reforma sanitária culminaram no texto constitucional de 1988, que consagrou os princípios fundamentais que orientam a política de saúde no $\mathrm{Brasil}^{20}$.

Desse modo, a "universalização da saúde pela via constitucional" ${ }^{21}$ conferiu à saúde o status de direito social fundamental sujeito a prestações positivas, estabelecendo novos padrões de relacionamento do Estado com a sociedade, mediados pela concepção de cidadania universal como característica estruturante do modelo de proteção social.

Desse processo de constitucionalização do direito à saúde no Brasil na perspectiva da seguridade social decorreram desdobramentos jurídicos e político-administrativos relacionados aos seguintes aspectos: (i) fundamentalidade formal e material do direito à saúde enquanto direito (do cidadão) e dever (do Estado); (ii) atribuição jurídica de relevância pública ao direito à saúde; (iii) constituição do direito à saúde como cláusula pétrea ${ }^{22}$; (iv) processo de institucionalização normativa da universalização da saúde e configuração de uma

\footnotetext{
${ }^{18}$ PAIM, Jairnilson Silva; ALMEIDA-FILHO, Naomar. Reforma sanitária brasileira em perspectiva e o SUS. In: PAIM, Jairnilson Silva; ALMEIDA-FILHO, Naomar (Orgs.) Saúde coletiva: teoria e prática. Rio de Janeiro: Medbook, 2014. p. 205.

${ }^{19}$ ASENSI, Felipe. op. cit.

${ }^{20}$ Id. Ibid., p.143.

${ }^{21}$ Id. Ibid.

${ }^{22}$ Id. Ibid.
} 
"juridicidade em rede"23; (v) redimensionamento das responsabilidades dos entes federativos no que diz respeito às ações e aos serviços de saúde; e (vi) inclusão de diferentes atores e instituições no campo da tutela e proteção ao direito à saúde.

Felipe Asensi argumenta que a incorporação da saúde ao ordenamento jurídico brasileiro como direito social fundamental, além de representar avanços, introduziu um conjunto de desafios tocantes a sua implementação e efetivação. Para o autor, esses desafios são de ordem diversificada e incluem, por exemplo, a formulação de arranjos econômicos e o estabelecimento de estratégias para a garantia do conteúdo prestacional do direito à saúde por diferentes atores, entre os quais "recebem destaque o Poder Judiciário e as instituições que compõem as denominadas funções essenciais da justiça" ${ }^{24}$ (destaques nossos).

Ainda segundo o autor, a partir do final dos nos 1980, o processo de constitucionalização dos direitos sociais no Brasil - mormente do direito à saúde -, combinado aos desafios de implementação/efetivação por parte do Estado, "fez com que tais direitos fossem cada vez mais submetidos ao crivo do Judiciário para obtenção do mandato de efetivação"25.

Assim, considerando a complexidade desses arranjos e o conjunto de conflitualidades que compõem a arena de disputas em torno da saúde, pode-se pensar que o campo da efetivação do direito à saúde no Brasil se constitui em uma zona de tensões entre o Estado e a sociedade civil mediada pelo sistema político e, sobretudo, pelo sistema do direito ${ }^{26}$ (Figura 1).

Nesse sentido, articulado a processos mais gerais de ampliação do poder institucional e de deslocamento da arena de decisões políticas para o Judiciário na sociedade brasileira ${ }^{27}$, um conjunto de demandas relativas à efetivação do direito à saúde (com destaque para acesso a serviços e ações de saúde) tem sido direcionado ao Estado por intermédio do sistema do direito, cujas comunicações sobre a matéria são predominantemente oriundas dos tribunais.

A literatura especializada tem denominado esse fenômeno de "judicialização das políticas públicas", que tem sido objeto de debates nas áreas da ciência política

\footnotetext{
${ }^{23}$ SARLET, Ingo Wolfgang; FIGUEIREDO, Mariana Filchtiner. Reserva do possível, mínimo existencial e direito à saúde: algumas aproximações. In: SARLET, Ingo Wolfgang; TIMM, Luciano Benetti (Orgs.), cit., p. 1350. Para os autores, a noção de juridicidade em rede compreende o arcabouço normativo, de caráter sistêmico, que se constitui referência para a proteção jurídica do direito à saúde enquanto direito humano e direito fundamental. Nessa perspectiva, inclui a produção normativa internacional de tutela do direito à saúde, bem como o complexo de instrumentos jurídicos nacionais composto pela Constituição Federal, leis, decretos, resoluções, recomendações e normas operacionais básicas, entre outros mecanismos normativos, que conferem institucionalidade ao direito social fundamental à saúde no Brasil.

${ }^{24}$ ASENSI, Felipe. op. cit., p. 199.

${ }^{25}$ Id. Ibid., p. 209.

${ }^{26}$ LUHMANN, Niklas. Law as a social system. Oxford: Oxford University Press, 2004.

${ }^{27}$ BARBOSA, Leon Victor de Queiroz. op. cit.
} 
e do direito, sobretudo em torno de questões tocantes às relações entre Estado e sociedade e às fronteiras da separação entre os poderes.

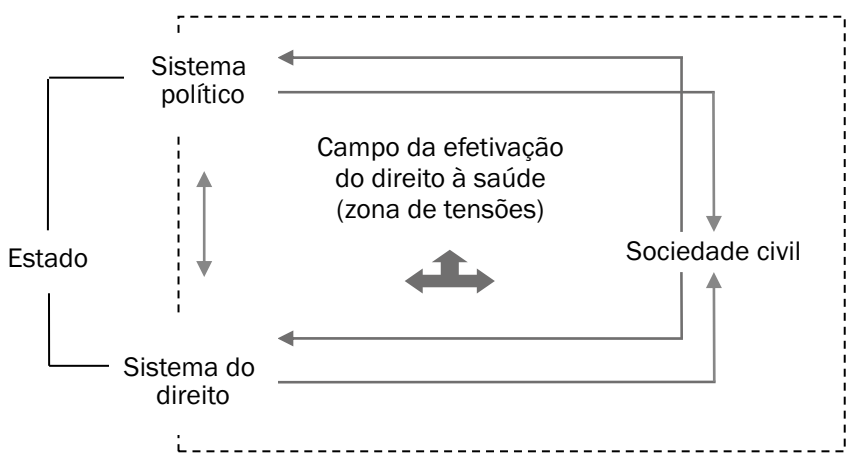

Fonte: Autoria própria

Figura 1. 0 campo de efetivação do direito à saúde no Brasil enquanto zona de tensões entre Estado e a sociedade civil

Desse modo, é no âmbito dessas tensões Estado-sociedade e do aprofundamento do processo de "densificação da via judicial" como fonte reivindicatória da efetivação do direito à saúde no Brasil ${ }^{28}$ que a análise das decisões do STJ sobre saúde no Brasil se situa, à luz das noções de "reserva do possível" e "mínimo existencial".

\section{Considerações sobre "mínimo existencial" e "reserva do possível"}

Ingo Sarlet e Mariana Figueiredo ${ }^{29}$ argumentam que as noções de "mínimo existencial" e "reserva do possível" têm suas bases dogmáticas assentadas no Direito alemão, o que nos fornece pistas para o reconhecimento desses institutos no âmbito do arcabouço jurídico-institucional e político-administrativo do Estado Social alemão e das expressões dos respectivos modelos de proteção social. Assim, o recurso às referidas categorias possibilita estabelecer pontos de contato entre a política e o direito no tocante à fixação jurídico-política dos limites da extensão/ retração do Welfare e da intervenção estatal em diferentes contextos e conjunturas socioeconômicos.

Segundo os autores, na elaboração da doutrina alemã, entre o final da década de 1940 e o início dos anos 1950, o mínimo existencial foi definido como o

\footnotetext{
${ }^{28}$ ASENSI, Felipe. op. cit.

${ }^{29}$ SARLET, Ingo Wolfgang; FIGUEIREDO, Mariana Filchtiner. Reserva do possível, mínimo existencial e direito à saúde: algumas aproximações. In: SARLET, Ingo Wolfgang; TIMM, Luciano Benetti (Orgs.), cit., p. 13-50.
} 
"conjunto de prestações materiais indispensáveis para assegurar a cada pessoa uma vida condigna, no sentido de uma vida saudável"30.

Também no direito alemão foram estabelecidas juridicamente as dimensões constitutivas básicas do mínimo existencial, a saber: mínimo fisiológico, que compreende as condições materiais básicas para uma vida digna e se funda no direito à vida e no princípio da dignidade humana; e mínimo sociocultural, que se refere às condições para a inserção do indivíduo na vida social e se fundamenta nos princípios do Estado Social e no conteúdo material do princípio da igualdade.

Desse modo, a delimitação/regulamentação, pelo campo jurídico, do alcance, do conteúdo e da incidência da prestação positiva do Estado em matéria de direito subjetivo e de direito fundamental concorre para a própria circunscrição das fronteiras políticas do Welfare (Figura 2).

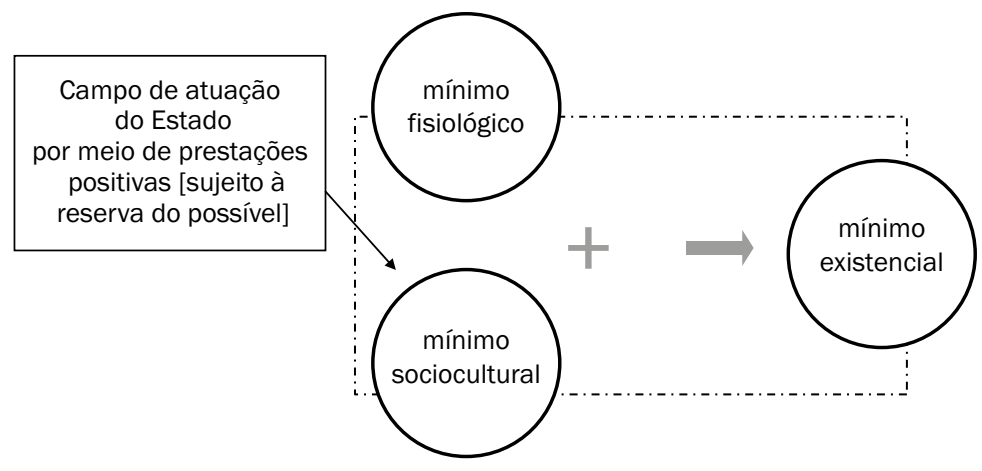

Fonte: Elaboração própria.

Figura 2. Dimensões do mínimo existencial e delimitação jurídica do campo de extensão das prestações positivas do Estado.

Ingo Sarlet e Mariana Figueiredo ${ }^{31}$ destacam que duas perspectivas argumentativas se complementam no debate jurídico alemão acerca do mínimo existencial. Articulado à ideia de a garantia das condições elementares de existência dos indivíduos compor o conteúdo basilar do Estado Social, o entendimento da doutrina constitucional e da jurisprudência germânicas é de que a dignidade humana não comporta quantificação e, assim, a definição do valor da prestação assistencial relaciona-se com a disponibilidade de recursos econômicos, com as expectativas sociais historicamente construídas e com questões da conjuntura política.

\footnotetext{
${ }^{30}$ SARLET, Ingo Wolfgang; FIGUEIREDO, Mariana Filchtiner. Reserva do possível, mínimo existencial e direito à saúde: algumas aproximações. In: SARLET, Ingo Wolfgang; TIMM, Luciano Benetti (Orgs.), cit., p. 25.

${ }^{31}$ ld. Ibid., p. 13-50.
} 
A necessária fixação, portanto, do valor da prestação assistencial destinada à garantia das condições existenciais mínimas, em que pese sua viabilidade, é, além de condicionada espacial e temporalmente, dependente também do padrão socioeconômico vigente. Não se pode, outrossim, negligenciar a circunstância de que o valor necessário para a garantia das condições mínimas de existência evidentemente estará sujeito a câmbios, não apenas no que diz respeito a esfera econômica e financeira, mas também no concernente às expectativas e necessidades do momento ${ }^{32}$.

Nos anos 1970, a doutrina alemã sistematizou a ideia de reserva do possível, que consiste em uma limitação fática e jurídica à efetivação de direitos fundamentais. Assim, "a efetividade dos direitos sociais a prestações materiais estaria sob a reserva das capacidades financeiras do Estado, uma vez que seriam direitos fundamentais dependentes de prestações financiadas pelos cofres públicos"33.

Nesses termos, é plausível pensar que a ideia de reserva do possível conferiu forma jurídica a condicionantes políticos (discricionariedade de decisões governamentais e parlamentares materializadas em deliberação orçamentária) e econômicos (capacidade financeira do Estado) da efetividade dos direitos sociais (fundamentais), sobretudo no tocante a seu componente sujeito a intervenções positivas do Estado.

Considerando essa formulação, Ingo Sarlet e Mariana Figueiredo afirmam que a categoria "reserva do possível" é formada por uma "dimensão tríplice", qual seja, a disponibilidade fática de recursos, a disponibilidade jurídica de recursos materiais e humanos e a proporcionalidade da prestação social.

Para os autores, o primeiro componente diz respeito, no entendimento jurídico majoritário, à disponibilidade fática de recursos para a satisfação das prestações positivas pelo Estado, ou seja, refere-se à existência/previsão de recursos financeiros, materiais e humanos para efetivação de direitos sociais em sua dimensão prestacional. Contudo, para os autores, o aspecto econômico dos direitos sociais é mais abrangente e tem natureza direta e indireta, alcançando, portanto, as duas dimensões básicas dos direitos sociais, que são o direito a prestações e o direito de defesa. Desse modo, na perspectiva dos autores, a variável "custo" consiste em um elemento característico dos direitos sociais em sentido lato e não configura uma especificidade dos direitos prestacionais ${ }^{34}$. Vale destacar que, no tocante ao direito à saúde no Brasil, há estudos que evidenciam a magnitude do gasto tributário (gasto indireto) em saúde, que se operacionaliza sob a forma

\footnotetext{
${ }^{32}$ SARLET, Ingo Wolfgang; FIGUEIREDO, Mariana Filchtiner. Reserva do possível, mínimo existencial e direito à saúde: algumas aproximações. In: SARLET, Ingo Wolfgang; TIMM, Luciano Benetti (Orgs.), cit., p. 21.

${ }^{33}$ Id. Ibid., p. 29.

${ }^{34}$ OCKÉ-REIS, Carlos; GAMA, Felipe Nogueira da. Nota técnica n. 19: Radiografia do gasto tributário em saúde: 2003-2013. Brasilia: IPEA, 2016. Disponível em: <http://www.ipea.gov.br/portal/images/stories/PDFs/nota_ tecnica/160530_nt_19_radiografia_gasto_tributario_saude_2003_2013.pdf>. Acesso em: 04 jun. 2016.
} 
de renúncia da arrecadação fiscal e redunda em impactos significativos sobre o financiamento público do Sistema Único de Saúde (SUS).

Complementarmente, o segundo elemento constitutivo da noção de reserva do possível diz respeito à disponibilidade jurídica dos recursos materiais e humanos que consiste na capacidade jurídica do Estado de decidir, segundo orientação discricionária, sobre a alocação de recursos para a efetivação de direitos sociais em seu caráter de prestações positivas. Assim, a disponibilidade jurídica dos recursos materiais e humanos está vinculada "à distribuição das receitas e competências tributárias, orçamentárias, legislativas e administrativas" ${ }^{\text {"35 }}$.

O terceiro elemento, para os autores, diz respeito à proporcionalidade da prestação social e se apresenta como o ponto de equilíbrio para a efetivação da proteção jurídica aos direitos fundamentais, a exemplo do direito à saúde. Dito de outro modo, a dimensão da proporcionalidade em consonância com o princípio da razoabilidade pode estabelecer limites à titularidade de um direito a prestações positivas e à exigibilidade desse direito para que o núcleo essencial de outro direito fundamental seja preservado.

[...] a reserva do possível constitui, em verdade (considerada toda a sua complexidade), espécie de limite jurídico e fático dos direitos fundamentais, mas também poderá atuar, em determinadas circunstâncias, como garantia dos direitos fundamentais, por exemplo, na hipótese de conflito de direitos, quando se cuidar da invocação - desde que observados os critérios da proporcionalidade e da garantia do mínimo existencial em relação a todos os direitos fundamentais - da indisponibilidade de recursos com o intuito de salvaguardar o núcleo essencial de outro direito fundamental ${ }^{36}$.

Em consonância com os argumentos sustentados pelos autores acerca da "dimensão tríplice" da reserva do possível, pode-se inferir que, na perspectiva dos autores, a aludida categoria jurídica não figura como um aspecto constituinte do núcleo básico dos direitos fundamentais.

De outro lado, o exame dos argumentos presentes na literatura especializada permite depreender que, no âmbito do pensamento jurídico, a dimensão econômica dos direitos sociais (face que dialoga com o conteúdo sujeito à prestação positiva material do Estado) constitui-se no ponto de confluência e articulação teórica entre o mínimo existencial e a reserva do possível enquanto categorias jurídicas.

\footnotetext{
${ }^{35}$ SARLET, Ingo Wolfgang; FIGUEIREDO, Mariana Filchtiner. Reserva do possível, mínimo existencial e direito à saúde: algumas aproximações. In: SARLET, Ingo Wolfgang; TIMM, Luciano Benetti (Orgs.), cit., p. 30.

${ }^{36}$ Id. Ibid., p. 30.
} 


\subsection{Mínimo existencial e reserva do possível no ordenamento jurídico brasileiro: pontos de contato com o direito à saúde}

A emergência das categorias "mínimo existencial" e "reserva do possível" no campo doutrinário brasileiro data do final da década de $1980^{37}$, período marcado no plano jurídico-político pela redemocratização do país e pelo redimensionamento das relações Estado-sociedade via ação política e constitucionalização da seguridade social, com a inscrição, no artigo $6^{\circ}$ da Constituição Federal de 1988 (CF/1988), dos direitos sociais como direitos de cidadania: "Art. $6^{\circ}$ São direitos sociais a educação, a saúde, a alimentação, o trabalho, a moradia, o transporte, o lazer, a segurança, a previdência social, a proteção à maternidade e à infância, a assistência aos desamparados, na forma desta Constituição" ${ }^{38}$.

A Constituição de 1988 consagrou os novos princípios de reestruturação do sistema de políticas sociais, segundo as orientações valorativas então hegemônicas: o direito social como fundamento da política; o comprometimento do Estado com o sistema, projetando um acentuado grau de provisão estatal pública e o papel complementar do setor privado; a concepção da seguridade social (e não de seguro) como forma mais abrangente de proteção ${ }^{39}$.

A partir do final dos anos 1980, observa-se um processo de inflexão político-jurídica no modelo de proteção social no Brasil, ao qual se integram a constitucionalização dos direitos sociais segundo princípios universalistas e a ampliação formal do escopo da ação do Estado no tocante às políticas sociais, sobretudo no que diz respeito às prestações materiais relativas ao aumento da cobertura populacional e à extensão da cesta de serviços, por exemplo, no campo da saúde. Já no plano macroeconômico, a conjuntura caracterizou-se por crise financeira e redução de recursos governamentais para o financiamento da seguridade social prevista pela nova ordem constitucional.

Todos esses fatores concorreram para alimentar o debate jurídico brasileiro sobre a efetividade dos direitos sociais, mormente do direito à saúde, em sua interface com a discussão sobre reserva do possível e mínimo existencial. Cabe ressaltar que, considerando os objetivos do estudo, embora reconheça-se a amplitude das nuances presentes na abordagem jurídica nacional a esse respeito, serão enfatizados argumentos especificamente relativos aos pontos de contato entre o mínimo existencial, a reserva do possível e o direito à saúde em nosso contexto.

\footnotetext{
${ }^{37}$ TORRES, Ricardo Lobo. O mínimo existencial e os direitos fundamentais. Revista de Direito Administrativo. Rio de Janeiro,v.177, p. 29-49, jul./set. 1989. e-ISSN:2238-5177. Disponivelem: <http://bibliotecadigital.fgv.br/ ojs/index.php/rda/article/download/46113/44271>. http://dx.doi.org/10.12660/rda.v177.1989.46113.

${ }^{38}$ BRASIL. Constituição da República Federativa do Brasil. Disponível em: <http://www.planalto.gov.br/ ccivil_03/constituicao/constituicaocompilado.htm>. Acesso em: 23 maio 2016.

${ }^{39}$ DRAIBE, Sônia. A política social no período FHC e o sistema de proteção social. Tempo Social, São Paulo, v. 15, n. 2, p. 63-101, nov. 2003. Disponível em: <http://www.scielo.br/pdf/ts/v15n2/a04v15n2.pdf>. Acesso em: 26 maio 2016. http://dx.doi.org/10.1590/S0103-20702003000200004.
} 
O exame da literatura nacional aponta para o emprego polissêmico dos termos "mínimo existencial" e "reserva do possível" no pensamento jurídico brasileiro. Considerando os esforços dos autores em estabelecer definições para as referidas categorias, identificou-se, nomeadamente nos trabalhos que tematizam o direito à saúde, três grandes linhas argumentativas que inscrevem a reserva do possível e o mínimo existencial no campo doutrinário, respectivamente, sob o registro de cláusulas gerais ${ }^{40} \mathrm{e}$ de princípios ${ }^{41,42}$, ou ainda, como critérios materiais "para assegurar a eficácia e a efetividade dos direitos fundamentais" ${ }^{33}$.

Do ponto de vista interpretativo, a análise da literatura evidencia que o debate jurídico no Brasil acerca do mínimo existencial e da reserva do possível orbita em torno de dois polos discursivos cujo núcleo central de divergência abrange, nomeadamente, questões relacionadas à concepção de Estado, à constitucionalidade e à fundamentalidade dos direitos sociais no ordenamento nacional, entre eles o direito à saúde - especialmente no que diz respeito à delimitação jurídica do conteúdo do mínimo existencial e do objeto de prestações materiais do Estado.

Nesses termos, o primeiro polo discursivo reúne autores que advogam, em linhas gerais, a condicionalidade da efetivação/eficácia dos direitos sociais (fundamentais) - por meio de prestações estatais de cunho material e positivo - a princípios orçamentários e à disponibilidade de recursos econômicos. Assim, segundo a literatura evidencia, estes dois aspectos se apresentam como componentes da noção de reserva do possível, bem como assumem forma e conteúdo diversificados em função da especificidade dos contextos locais.

Nesse campo, não obstante os matizes analíticos, pode-se situar ilustrativamente os trabalhos de Ricardo Torres ${ }^{44} \mathrm{e}$ as denominadas "teses da UERJ"45, que compreendem um eixo argumentativo desenvolvido em dissertações de mestrado e teses de doutoramento produzidas no âmbito do Programa de Pós-Graduação em Direito da Universidade do Estado do Rio de Janeiro no qual se sublinha juridicamente a ideia de custo enquanto elemento característico dos direitos fundamentais e interconectado ao dimensionamento da extensão da tutela do Estado a estes direitos por meio de ações positivas.

\footnotetext{
${ }^{40}$ TORRES, Ricardo Lobo. 0 mínimo existencial, os direitos sociais e os desafios de natureza orçamentária. In: SARLET, Ingo Wolfgang; TIMM, Luciano Benetti (Orgs.). Direitos fundamentais: orçamento e "reserva do possível". Porto Alegre: Livr. do Advogado, 2013. p. 63-78.

${ }^{41}$ ZANITELLI, Leandro Martins. Custos ou competências? Uma ressalva à doutrina da reserva do possível. In: SARLET, Ingo Wolfgang; TIMM, Luciano Benetti (Orgs.). Direitos fundamentais: orçamento e "reserva do possível". Porto Alegre: Livr. do Advogado, 2013. p. 187-236.

${ }^{42}$ PEIXOTO NETO, Pedro Accioly de Sá; ACCIOLY, Nadja Valéria da C. Campos. Sentido e amplitude da reserva do possível em matéria de saúde. Revista SJRJ, Rio de Janeiro, v. 19, n. 34, p. 163-172, ago. 2012. Disponível em: <https://www.jfr.jus.br/sites/default/files/revista-sjij/arquivo/344-1433-1-pb.pdf>.

${ }^{43}$ SARLET, Ingo Wolfgang; FIGUEIREDO, Mariana Filchtiner. Reserva do possível, mínimo existencial e direito à saúde: algumas aproximações. In: SARLET, Ingo Wolfgang; TIMM, Luciano Benetti (Orgs.), cit., p. 14.

${ }^{44}$ TORRES, Ricardo Lobo. 0 mínimo existencial e os direitos fundamentais, cit., p. $29-49$.

${ }^{45}$ Id. TORRES, Ricardo Lobo. 0 mínimo existencial, os direitos sociais e os desafios de natureza orçamentária, cit., p. 63-78.
} 
O segundo polo discursivo compõe-se de construções argumentativas que vinculam o mínimo existencial à ideia de fundamentalidade formal e material dos direitos sociais na ordem constitucional brasileira, bem como entendem a noção de reserva do possível como um critério jurídico fático/material não necessariamente limitador da efetivação dos direitos sociais fundamentais em seu caráter prestacional. Neste campo, há destaque, mormente, para a produção jurídica de Ingo Sarlet e Mariana Figueiredo ${ }^{46,47}$ e os trabalhos acadêmicos orientados pelo autor no âmbito do Programa de Pós-Graduação em Direito da Pontifícia Universidade Católica do Rio Grande do Sul (PUC-RS).

Os trabalhos que tematizam o direito à saúde no Brasil em suas conexões com as ideias de mínimo existencial e reserva do possível inscrevem-se nas vertentes discursivo-interpretativas anteriormente mencionadas. Destarte, parte da literatura filia-se à corrente doutrinária que advoga a constitucionalização da saúde como direito social e a fundamentalidade do direito à saúde, com base em uma abordagem hermenêutica e principiológica da ordem constitucional.

Diante do exposto, é possível depreender que os posicionamentos doutrinários e as decisões judiciais acerca da concretização dos direitos fundamentais sociais, a exemplo do direito à saúde, situam-se na zona de fronteira entre a política e o direito, assim como dialogam com as complexas configurações sócio-históricas assumidas pelos Welfare States nos diversos contextos. Desse modo, no campo doutrinário são constituídas arenas discursivas de disputas simbólicas mediadas por concepções de Estado e juridicamente operacionalizadas pelas categorias "reserva do possível" e "mínimo existencial".

\section{Reserva do possível e mínimo existencial: contornos jurídico-políticos do direito à saúde nas decisões do STJ entre 2010 e 2016}

No Brasil, a atuação do STJ em matéria de saúde articula-se ao processo de constitucionalização do direito à saúde e à ampliação do poder decisório do Judiciário sobre questões políticas oriundas das tensões entre o Estado e a sociedade, principalmente no que se refere a conflitos e disputas no plano da efetivação do direito fundamental à saúde, como discutido anteriormente.

O corpus dos julgados em análise é composto, em sua maioria, por decisões colegiadas em sede de recurso especial cujos argumentos de pedido de revisão à Corte fundamentam-se, mormente, em alegações de contrariedade à Lei n. 8.080/199048.

\footnotetext{
${ }^{46}$ SARLET, Ingo Wolfgang; FIGUEIREDO, Mariana Filchtiner. Reserva do possível, mínimo existencial e direito à saúde: algumas aproximações. In: SARLET, Ingo Wolfgang; TIMM, Luciano Benetti (Orgs.), cit., p. 13-50.

${ }^{47}$ Id. Reserva do possível, mínimo existencial e direito à saúde: algumas aproximações. Revista de Doutrina da $4^{a}$ Região, Porto Alegre, n. 24, jul. 2008. Disponível em: <http://www.revistadoutrina.trf4.jus.br/artigos/ edicao024/ingo_mariana.html>. Acesso em: 13 jun. 2016.

${ }^{48}$ BRASIL. Lei n. 8.080, de 19 de setembro de 1990. Dispõe sobre as condições para a promoção, proteção e recuperação da saúde, a organização e o funcionamento dos serviços correspondentes e dá outras providências. Disponível em: <http://conselho.saude.gov.br/legislacao/lei8080_190990.htm>. Acesso em: 02 abr. 2018.
} 
Além dos recursos especiais, também integram o corpus, com menor expressividade e frequência, recurso ordinário e agravo regimental em recurso especial.

Nas 15 decisões estudadas, identificou-se como objeto de disputa jurídica dirigida ao STJ a efetivação de prestações materiais em saúde relacionadas ao provimento de insumos (medicamentos e equipamentos) e de serviços (ações terapêuticas individuais e ações coletivas intersetoriais de saúde), à infraestrutura de estabelecimentos de saúde e à implementação de programas de saúde indígena - demanda esta não reconhecida pela Corte com base em argumento de ordem processual concernente à incompetência para julgar matérias de natureza constitucional.

Em sentido geral e abstrato, os bens e serviços de saúde formulados e levados à apreciação do STJ como objeto de prestação estatal positiva a ser garantida pela administração pública (a exemplo de medicamentos, equipamentos médicos hospitalares, procedimentos terapêuticos, entre outros) constituem conteúdo material do direito à saúde. De outro lado, paradoxalmente, as respostas institucionais às demandas judiciais em saúde expressam tensões entre Estado e sociedade no campo da efetivação, que perpassam questões tocantes ao financiamento, à gestão, à infraestrutura, à organização e à atenção à saúde no âmbito do SUS, além de mobilizar racionalidades distintas no processo de tomada de decisões jurídicas e político-administrativas.

Assim, nos litígios em tela, identificou-se a predominância de estados e de municípios como partes a pleitear ao STJ revisão de decisões judiciais contrárias à fazenda pública e favoráveis a prestações estatais em saúde para indivíduos e/ou para a coletividade. Considerando o recorte empírico, a reforma de decisões judiciais da segunda instância pelo STJ foi observada nos casos em que o Ministério Público figurou como recorrente e a Administração, como recorrida na disputa judicial em torno da efetivação de ações coletivas e/ou intersetoriais de saúde - a exemplo da instalação de redes de esgotamento sanitário pelo município e da provisão de equipamentos a unidades hospitalares da rede pública de saúde pelo estado.

A análise documental evidenciou a tendência da Corte de manter as decisões judiciais recorridas e não dar provimento aos pedidos recursais interpostos pela Administração. O entendimento jurisprudencial do STJ aponta no sentido de reconhecer e deferir pleitos de particulares ou do Ministério Público em matéria de direito à saúde, bem como de obrigar o poder público ao cumprimento de prestações estatais positivas no campo da política de saúde.

Depreende-se que o discurso jurídico do STJ referente às matérias de direito à saúde se assentou, em linhas gerais, na afirmação jurídica dos seguintes aspectos: constitucionalidade do direito social à saúde; efetividade das normas constitucionais programáticas tocantes ao direito à saúde; dignidade da pessoa humana como valor constitucional articulado ao direito à saúde; fundamentos e objetivos republicanos previstos nos artigos $1^{\circ}$ e $3^{\circ}$ da Constituição Federal na interface com o direito à 
saúde; responsabilidade solidária da União, estados e municípios no que toca à efetivação judicial do direito à saúde ${ }^{49},{ }^{50}$; e admissibilidade do bloqueio de verbas públicas como uma medida jurídica de ajuste da discricionariedade administrativa em função da garantia de efetividade do conteúdo do direito à saúde (Figura 3).

Em articulação com esses argumentos, no tocante ao manejo discursivo da aplicabilidade das categorias "mínimo existencial" e "reserva do possível" às matérias de direito à saúde, identificou-se aderência do STJ ao entendimento do Supremo Tribunal Federal (STF) no sentido de afastar a adoção da "cláusula da reserva do possível” em casos relativos à salvaguarda de direito à vida e à saúde:

[...] a cláusula da "reserva do possível" - ressalvada a ocorrência de justo motivo objetivamente aferível - não pode ser invocada, pelo Estado, com a finalidade de exonerar-se do cumprimento de suas obrigações constitucionais, notadamente quando, dessa conduta governamental negativa, puder resultar nulificação ou, até mesmo, aniquilação de direitos constitucionais impregnados de um sentido de essencial fundamentalidade ${ }^{51}$.

Nos documentos pesquisados, têm-se como principais características do núcleo jurídico-discursivo-decisório do STJ: a afirmação da tutela de um mínimo existencial em saúde juridicamente delimitado; a refutação da tese da reserva do possível em matéria de direito à saúde, exceto quando houver comprovação objetiva da incapacidade econômico-financeira da Administração; e o afastamento da separação de poderes como impeditivo à edição de mandamento realizador pelo Judiciário no que toca à efetivação do direito à saúde (Figura 3).

\footnotetext{
${ }^{49}$ ASENSI, Felipe. Responsabilidade solidária dos entes da federação e "efeitos colaterais" no direito à saúde. Revista de Direito Sanitário, São Paulo, v. 16 n. 3, p. 145-156, nov. 2015/fev. 2016. Disponível em: <http:// www.revistas.usp.br/rdisan/article/view/111658/109689>. Acesso em: 13 jun. 2016. http://dx.doi. org/10.11606/issn.2316-9044.v16i3p145-156.

${ }^{50}$ WANG, Daniel Wei L. et al. Os impactos da judicialização da saúde no município de São Paulo: gasto público e organização federativa. Revista de Administração Pública, Rio de Janeiro, v. 48, n. 5, p. 11911202, set./out. 2014. Disponível em: <http://www.scielo.br/pdf/rap/v48n5/06.pdf>. http://dx.doi. org/10.1590/0034-76121666.

${ }^{51}$ BRASIL. Supremo Tribunal Federal. ADPF 45 MC/DF. ADPF Políticas Públicas - Intervenção Judicial - "Reserva do Possível". Arguição de Descumprimento de Preceito Fundamental. A questão da legitimidade constitucional do controle e da intervenção do Poder Judiciário em tema de implementação de políticas públicas, quando configurada hipótese de abusividade governamental. Dimensão política da jurisdição constitucional atribuída ao Supremo Tribunal Federal. Inoponibilidade do arbítrio estatal à efetivação dos direitos sociais, econômicos e culturais. Caráter relativo da liberdade de conformação do legislador. Considerações em torno da cláusula da "reserva do possível". Necessidade de preservação, em favor dos indivíduos, da integridade e da intangibilidade do núcleo consubstanciador do "mínimo existencial". Viabilidade instrumental da arguição de descumprimento no processo de concretização das liberdades positivas (direitos constitucionais de segunda geração). Relator: Ministro Celso de Mello. Brasília, 4 de maio de 2004. Disponível em: <http:// www.stf.jus.br/arquivo/informativo/documento/informativo345.htm\#ADPF\%20-\%20Pol\%C3\%ADticas\%20 P\%C3\%BAblicas\%20-\%20Interven\%C3\%A7\%C3\%A30\%20Judicial\%20-\%20\%22Reserva\%20do\%20 Poss\%C3\%ADvel\%22\%20(Transcri\%C3\%A7\%C3\%B5es)>. Acesso: 03 abr. 2018.
} 
Nas decisões examinadas, o STJ estabeleceu fronteiras jurídicas delimitadoras do campo de atuação prestacional do Estado no âmbito do direito à saúde a partir da fixação do conteúdo do mínimo existencial em saúde (Figura 3) e da relativização do poder discricionário do Executivo, juridicamente operacionalizada pela imposição de mandamento realizador por meio da intervenção judicial no campo da política social de saúde.

Caracterização do núcleo discursivo-decisório dos julgados do STJ sobre direito à saúde, mínimo existencial e reserva do possível entre 2010-2016

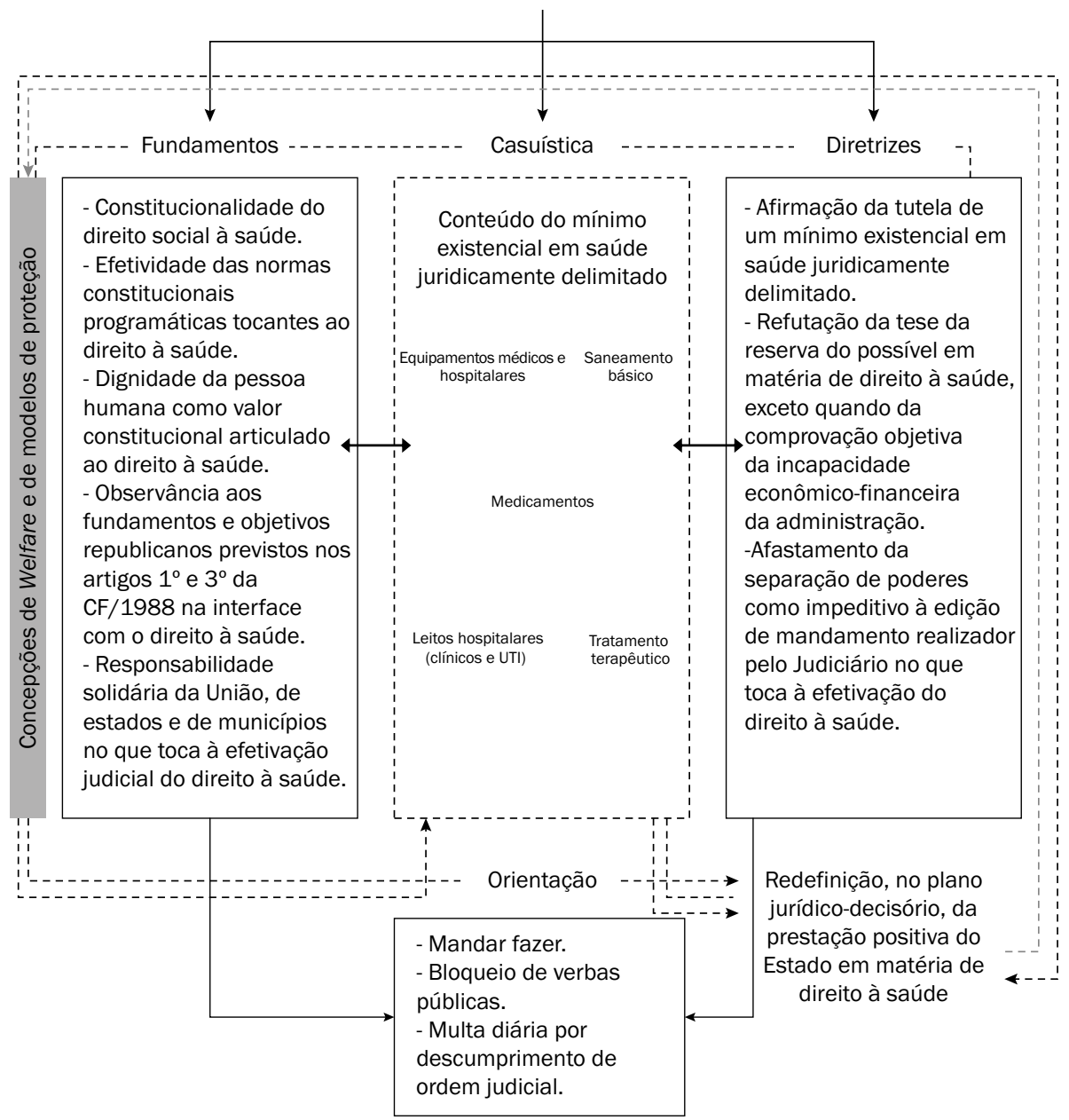

Fonte: Elaboração própria.

Figura 3. Caracterização do núcleo discursivo-decisório dos julgados do STJ sobre direito à saúde, mínimo existencial e reserva do possível entre 2010-2016. 
As decisões do STJ delineiam o mínimo existencial em saúde a partir da atribuição de legitimidade jurídica acerca do que pode ser conhecido como conteúdo de direito à saúde e, portanto, sujeito a prestações materiais do Estado. Nos documentos em análise, o conteúdo do mínimo existencial juridicamente delimitado circunscreve-se a medicamentos, leitos hospitalares (clínicos e de UTI), equipamentos médico-hospitalares, tratamento terapêutico e saneamento básico (Figura 3), vinculando-se predominantemente a ações de assistência e recuperação, com baixo elo comunicativo com o conceito ampliado de saúde. Cabe ressaltar que a definição desse conteúdo jurídico é mediada pela natureza das ações reivindicatórias de efetivação do direito à saúde direcionadas à Corte.

Outro aspecto apontado pela análise documental diz respeito à natureza individual das demandas dirigidas ao STJ relativas ao direito à saúde, com destaque para os litígios nos quais figuram como partes indivíduos e administração (municipal/estadual), tendo como objeto de disputa o fornecimento de medicamentos pelo Sistema Único de Saúde (SUS). A este respeito, ressalta-se que, na maior parte dos julgados concernentes à provisão de medicamentos, não constam informações detalhadas sobre a substância requerida pelas partes ao poder público - a exemplo de sua previsão na Relação Nacional de Medicamentos Essenciais (Rename) no âmbito do SUS. O discurso jurídico mobiliza termos como "medicamento de alto custo" e "medicamento de uso imprescindível" para caracterizar os medicamentos pleiteados e judicialmente concedidos. Em geral, o STJ tendeu a sublinhar em suas decisões a dimensão da tutela individual do direito à saúde em detrimento de sua dimensão coletiva e do caráter de "juridicidade em rede" 52 , que conformam o campo da regulamentação sanitária no Brasil.

Assim, em consonância com outros estudos sobre judicialização da saúde ${ }^{53}$, os achados deste trabalho indicam que as decisões do STJ basearam-se em leituras abstratas dos princípios constitucionais, desconectadas do aparato normativo infraconstitucional que confere institucionalidade jurídico-política ao direito à saúde no Brasil - a exemplo dos princípios e diretrizes estratégicas do SUS e, nos casos específicos de disputa judicial por concessão de medicamentos, da Política Nacional de Medicamentos ${ }^{54}$ e da Política Nacional de Assistência Farmacêutica ${ }^{55}$.

\footnotetext{
${ }^{52}$ SARLET, Ingo Wolfgang; FIGUEIREDO, Mariana Filchtiner. Reserva do possível, mínimo existencial e direito à saúde: algumas aproximações. Revista de Doutrina da $4^{a}$ Região, cit.

${ }^{53}$ WANG, Daniel Wei L. et al. op. cit., p.1191-1202.

${ }^{54}$ BRASIL. Ministério da Saúde. Portaria GM n. 3.916, 30 de outubro de 1998. Aprova a Política Nacional de Medicamentos. Disponivel em: <http://bvsms.saude.gov.br/bvs/publicacoes/politica_medicamentos. pdf>. Acesso em: 13 jun. 2016.

${ }^{55}$ BRASIL. Ministério da Saúde. Resolução CNS n. 338, de 06 de maio de 2004. Aprova a Política Nacional de Assistência Farmacêutica. Disponivel em: <http://bvsms.saude.gov.br/bvs/saudelegis/cns/2004/ res0338_06_05_2004.html>. Acesso em: 13 jun. 2016.
} 
A inobservância do caráter sistêmico dos mecanismos jurídicos de proteção em rede do direito à saúde no ordenamento brasileiro pelo STJ, nas decisões em tela neste estudo, também é indicada pelo posicionamento da Corte relativo à afirmação jurídica da responsabilidade solidária dos entes federativos em matéria de saúde, designadamente no tocante ao fornecimento e ao custeio de medicamento pelo SUS. De modo geral, o entendimento do STJ suprime, no plano jurídico-discursivo e no horizonte decisório, as diretrizes estratégicas de organização/gestão do SUS e as regras administrativas de repartição de competências e responsabilidades federativas no âmbito do SUS, o que concorre para a mitigação dos dispositivos de gestão e do funcionamento das políticas de saúde ${ }^{56}$.

De outro lado, o discurso jurídico do STJ sobre o direito à saúde também redefine, no campo decisório judicial, os destinatários da prestação estatal positiva em saúde, sublinhando-os como "pessoas carentes" e "pessoas desprovidas de recursos financeiros". Dessa forma, opera, ainda que de modo implícito, concepções de Welfare e de modelos de proteção. Destarte, a análise dos dados evidencia que o campo decisório do STJ em matéria de saúde é marcado por paradoxos em questões como a universalidade/focalização da política social de saúde, o caráter individual/ coletivo do direito à saúde e a natureza política/jurídica do processo decisório sobre demandas sanitárias.

\section{Considerações finais}

As noções de mínimo existencial e reserva do possível são categorias jurídicas alemãs que dialogam com as expressões do Welfare e seus modelos de proteção. Tais categorias ganham visibilidade no Direito brasileiro a partir do final dos anos 1980, com a constitucionalização do direito à saúde como direito fundamental e com a ampliação do poder institucional do Judiciário em nosso contexto.

No Brasil, as noções do mínimo existencial e da reserva do possível têm se configurado categorias jurídico-políticas na mediação, pelo Judiciário, de conflitos entre o Estado e a sociedade no plano da efetivação do direito à saúde.

Desse modo, no tocante ao emprego dessas categorias nas decisões do STJ sobre saúde, a análise dos dados evidencia que o entendimento da Corte sobre a efetivação do direito à saúde caracteriza-se pelo argumento da não "oponibilidade da reserva do possível ao mínimo existencial" em matéria de saúde, pela determinação ao Poder Executivo da obrigação de fazer, pela afirmação jurídica da responsabilidade solidária dos entes federativos em matéria de saúde e pela admissibilidade do bloqueio de verbas públicas, mormente quando se trata de garantia de acesso a medicamentos.

\footnotetext{
${ }^{56}$ ASENSI, Felipe. Responsabilidade solidária dos entes da federação e “efeitos colaterais” no direito à saúde, cit., p. 145-156.
} 
Ademais, nas decisões judiciais estudadas neste trabalho, há destaque para a refutação jurídico-política da ideia de separação de poderes como fator impeditivo à edição de mandamento realizador pelo Poder Judiciário em matéria de direitos sociais, bem como para a demarcação do conteúdo jurídico do mínimo existencial constitutivo do direito fundamental à saúde e, desse modo, do estabelecimento da extensão das prestações positivas do Estado.

Em linhas gerais, é possível depreender que a delimitação jurídica do mínimo existencial em saúde, presente no corpus de decisões do STJ analisado no estudo, caracteriza-se por tensões e paradoxos jurídico-políticos no plano da efetivação do direito à saúde que, por vezes, subvertem a própria estrutura formal e normativa de proteção nesse campo e redimensionam as fronteiras na esfera da implementação de políticas de saúde.

\section{Referências}

ASENSI, Felipe. Direito à saúde: práticas sociais reivindicatórias e sua efetivação. Curitiba: Juruá, 2013. 370p.

Responsabilidade solidária dos entes da federação e "efeitos colaterais" no direito à saúde. Revista de Direito Sanitário, São Paulo, v. 16 n. 3, p. 145-156, nov. 2015/fev. 2016. Disponível em: <http://www.revistas.usp.br/rdisan/article/view/111658/109689>. Acesso em: 13 jun. 2016. http://dx.doi.org/10.11606/issn.2316-9044.v16i3p145-156.

BARBOSA, Leon Victor de Queiroz. O silêncio dos incumbentes: fragmentação partidária e empoderamento judicial no Brasil, 2015. 166f. Tese (Doutorado) - Universidade Federal de Pernambuco, Programa de Pós-Graduação em Ciência Política, Recife, 2015. Disponível em: $<$ https://repositorio.ufpe.br/bitstream/123456789/15169/1/TESE\%20\%282015-02-23\%29\%20 -\%20LEON\%20VICTOR\%20DE\%20QUEIROZ\%20BARBOSA.pdf>.

BAUER, Martin W.; AARTS, Bas. A construção do corpus: um princípio para a coleta de dados qualitativos. In: BAUER, Martin. W.; GASKEL, George. Pesquisa qualitativa com texto, imagem e som: um manual prático. Petrópolis, RJ: Vozes, 2003. p. 39-63.

CELLARD, André. A análise documental. In: POUPART, Jean. et al. (Orgs.). A pesquisa qualitativa: enfoques epistemológicos e metodológicos. Petrópolis: Vozes, 2010, p. 295-316.

DI PIETRO, Maria Sílvia Zanella. Direito administrativo. São Paulo: Atlas, 2015.

DRAIBE, Sônia. A política social no período FHC e o sistema de proteção social. Tempo Social, São Paulo, v. 15, n. 2, p. 63-101, nov. 2003. Disponível em: <http://www.scielo.br/pdf/ts/v15n2/ a04v15n2.pdf > . Acesso em: 26 maio 2016. http://dx.doi.org/10.1590/S0103-20702003000200004.

O Welfare State no Brasil: características e perspectivas. Caderno de Pesquisa, Campinas, n. 8, 1993. Disponível em: <https://sociologiajuridica.files.wordpress.com/2011/10/ o-welfare-state-no-brasil-caracterc3adsticas-e-perspectivas-sonia-draibe.pdf $>$. Acesso em: 23 maio 2016. 
FLEURY, Sonia; OUVERNEY, Assis Mafort. Política de saúde: uma política social. In: GIOVANELLA, Ligia et al. (Org.). Políticas e sistema de Saúde no Brasil. Rio de Janeiro: FIOCRUZ: CEBES, 2008. p. 23-64.

GRINOVER, Ada Pellegrini. O controle das políticas públicas pelo poder judiciário. Revista do Curso de Direito da Faculdade de Humanidades e Direito, São Paulo, v. 7, n. 7, p. 9-37, 2010. Disponível em: <https://www.metodista.br/revistas/revistas-ims/index.php/RFD/ article/viewFile/1964/1969>.

LUHMANN, Niklas. Law as a social system. Oxford: Oxford University Press, 2004.

OCKÉ-REIS, Carlos; GAMA, Felipe Nogueira da. Nota técnica n. 19: Radiografia do gasto tributário em saúde: 2003-2013. Brasília: IPEA, 2016. Disponível em: <http://www.ipea.gov. br/portal/images/stories/PDFs/nota_tecnica/160530_nt_19_radiografia_gasto_tributario_ saude_2003_2013.pdf>. Acesso em: 04 jun. 2016.

PAIM, Jairnilson Silva; ALMEIDA-FILHO, Naomar. Reforma sanitária brasileira em perspectiva e o SUS. In: PAIM, Jairnilson Silva; ALMEIDA-FILHO, Naomar (Orgs.) Saúde coletiva: teoria e prática. Rio de Janeiro: Medbook, 2014. p. 201-209.

PEIXOTO NETO, Pedro Accioly de Sá; ACCIOLY, Nadja Valéria da C. Campos. Sentido e amplitude da reserva do possível em matéria de saúde. Revista SJRJ, Rio de Janeiro, v. 19, n. 34, p. 163-172, ago. 2012. Disponível em: <https://www.jfrj.jus.br/sites/default/files/revistasjrj/arquivo/344-1433-1-pb.pdf>.

SARLET, Ingo Wolfgang; FIGUEIREDO, Mariana Filchtiner. Reserva do possível, mínimo existencial e direito à saúde: algumas aproximações. In: SARLET, Ingo Wolfgang; TIMM, Luciano Benetti (Orgs.). Direitos fundamentais: orçamento e "reserva do possível". Porto Alegre: Livr. do Advogado, 2013. p. 13-50.

Reserva do possível, mínimo existencial e direito à saúde: algumas aproximações. Revista de Doutrina da $4^{a}$ Região, Porto Alegre, n. 24, jul. 2008. Disponível em: <http://www.revistadoutrina.trf4.jus.br/artigos/edicao024/ingo_mariana.html $>$. Acesso em: 13 jun. 2016.

TORRES, Ricardo Lobo. O mínimo existencial e os direitos fundamentais. Revista de Direito Administrativo. Rio de Janeiro, v. 177, n. 29-49, jul./set. 1989. e-ISSN: 2238-5177. Disponível em: <http://bibliotecadigital.fgv.br/ojs/index.php/rda/article/download/46113/44271>.http:// dx.doi.org/10.12660/rda.v177.1989.46113.

O mínimo existencial, os direitos sociais e os desafios de natureza orçamentária. In: SARLET, Ingo Wolfgang; TIMM, Luciano Benetti (Orgs.). Direitos fundamentais: orçamento e "reserva do possível". Porto Alegre: Livr. do Advogado, 2013. p. 63-78. 
Direito à saúde no Brasil: reserva do possível e mínimo existencial no STJ

VEÇOSO, Fábia Fernandes Carvalho et al. A pesquisa em Direito e as bases eletrônicas de julgados dos Tribunais: matrizes de análise e aplicação no Supremo Tribunal Federal e no Superior Tribunal de Justiça. Revista de Estudos Empíricos em Direito / Brazilian Journal of Empirical Legal Studies, v. 1, n. 1, p. 105-139, jan. 2014. ISSN 2319-0817. Disponível em: $<$ http://www.reedpesquisa.org/ojs-2.4.3/index.php/reed/article/view/10 $>$. Acesso em: 30 mar. 2015. http://dx.doi.org/10.19092/reed.v1i1.10.

WANG, Daniel Wei L. et al. Os impactos da judicialização da saúde no município de São Paulo: gasto público e organização federativa. Revista de Administração Pública, Rio de Janeiro, v. 48, n. 5, p. 1191-1202, set./out. 2014. Disponível em: <http://www.scielo.br/pdf/rap/v48n5/06. pdf>. http://dx.doi.org/10.1590/0034-76121666.

ZANITELLI, Leandro Martins. Custos ou competências? Uma ressalva à doutrina da reserva do possível. In: SARLET, Ingo Wolfgang; TIMM, Luciano Benetti (Orgs.). Direitos fundamentais: orçamento e "reserva do possível". Porto Alegre: Livr. do Advogado, 2013. p. 187-236.

Andrija Oliveira Almeida - Doutoranda em Ciências Sociais pela Universidade Federal da Bahia (UFBA); mestre em Saúde Comunitária pela UFBA; especialista em Metodologia do Ensino, Pesquisa e Extensão em Educação pela Universidade do Estado da Bahia (UNEB), graduada em Ciências Sociais pela UFBA; graduada em Pedagogia pela UNEB; graduada em Direito pela Universidade Católica de Salvador. Salvador/BA, Brasil. E-mail: andrija. oliveiraalmeida@gmail.com

Marco Valério Viana Freire - Especialista em Psicopedagogia Aplicada ao Desenvolvimento de Pessoas pela Faculdade de Educação da Bahia; especialista em Administração Pública pela Universidade Estadual de Feira de Santana; especialista em Direito Tributário pela Universidade Federal da Bahia. Professor de Direito Administrativo, Direito Financeiro e Direito Tributário no curso de graduação em Direito da Universidade Católica do Salvador. Advogado; Procurador do Estado da Bahia. Salvador/BA, Brasil. 